Gut and Liver, Vol. 11, No. 1, January 2017, pp. 149-155

\title{
Feasibility of Endoscopic Papillary Large Balloon Dilation in Patients with Difficult Bile Duct Stones without Dilatation of the Lower Part of the Extrahepatic Bile Duct
}

\author{
Yuji Fujita ${ }^{1}$, Akito Iwasaki $^{1}$, Takamitsu Sato ${ }^{1}$, Toshio Fujisawa ${ }^{2}$, Yusuke Sekino $^{1}$, Kunihiro Hosono $^{1}$, Nobuyuki Matsuhashi ${ }^{2}$, \\ Kentaro Sakamaki ${ }^{3}$, Atsushi Nakajima ${ }^{1}$, and Kensuke Kubota ${ }^{1}$ \\ ${ }^{1}$ Department of Gastroenterology and Hepatology, Yokohama City University School of Medicine, Yokohama, ${ }^{2}$ Department of Gastroenterology, \\ NTT Tokyo Medical Center, Tokyo, and ${ }^{3}$ Department of Medical Statistic, Yokohama City University School of Medicine, Yokohama, Japan
}

\begin{abstract}
Background/Aims: There is no consensus for using endoscopic papillary large balloon dilation (EPLBD) in patients without dilatation of the lower part of the bile duct (DLBD). We evaluated the feasibility and safety of EPLBD for the removal of difficult bile duct stones (diameter $\geq 10 \mathrm{~mm}$ ) in patients without DLBD. Methods: We retrospectively reviewed the records of 209 patients who underwent EPLBD for the removal of bile duct stones from October 2009 to July 2014. Primary outcomes were the clearance rate and additional mechanical lithotripsy. Secondary outcomes were the incidence of complications and recurrence rate. Results: Fiftyseven patients had DLBD (27.3\%), and 152 did not have DLBD (72.7\%). There were no significant differences in the overall success rate or the use of mechanical lithotripsy. Success rate during the first session and procedure time were better in the DLBD than the without-DLBD group $(75.7 \%$ vs $66.7 \%, 48.1 \pm 23.0$ minutes vs $58.4 \pm 31.7$ minutes, respectively). As for complications, there were no significant differences in the incidence of pancreatitis, perforation or bleeding after endoscopic retrograde cholangiopancreatography. The recurrence rate did not differ significantly between the two groups. Conclusions: EPLBD is a useful and safe method for common bile duct stone removal in patients without DLBD. (Gut Liver 2017;11:149-155)
\end{abstract}

Key Words: Cholangiopancreatography, endoscopic retrograde; Common bile duct stone

\section{INTRODUCTION}

Endoscopic sphincterotomy (EST) combined with mechanical lithotripsy (ML) is a feasible method for the removal of difficult biliary stones. However, we often encounter challenging cases that require multiple procedures and are complicated with post-endoscopic retrograde cholangiopancreatography (ERCP) pancreatitis, perforation, and massive bleeding. Endoscopic papillary balloon dilation (EPBD) was introduced in 1982 to preserve the sphincter function and decrease bleeding caused by EST. ${ }^{1}$ In 2004, a Japanese randomized controlled clinical trial of EPBD confirmed the safety and efficacy of this procedure for common bile duct (CBD) stones $<14 \mathrm{~mm}$ in diameter. ${ }^{2}$ However, some bile duct stones were difficult to remove because of their large size, rectangular shape of the CBD, or anatomical difficulties interfering with endoscopic procedures. In 2003, Ersoz et al. ${ }^{3}$ first reported the usefulness of large balloon dilation (12 to 20-mm diameter) after EST (endoscopic papillary large balloon dilation, EPLBD) for the removal of large bile duct stones. Since then, EPLBD has been used in Japan. Itoi et al. ${ }^{4}$ demonstrated the safety and feasibility of EPLBD and extended its application to multiple large stones $>13 \mathrm{~mm}$ in diameter. Difficult cases have been encountered with large stones and without dilatation of the lower part of the CBD (DLBD). The combination of EST and ML in such cases often requires multiple procedures, whereas EPLBD has been avoided so far because of the high risk of procedure-associated complications.

We hypothesized that the indications of EPLBD could be extended to include the treatment of difficult large stones without DLBD. The aim of this study was to verify the technical feasibil-

\footnotetext{
Correspondence to: Kensuke Kubota

Department of Gastroenterology and Hepatology, Yokohama City University School of Medicine, 3-9 Fukuura Kanazawa-ku, Yokohama 236-0004, Japan

Tel: +81-45-787-2800, Fax: +81-45-787-2866, E-mail: kubotak@yokohama-cu.ac.jp

Received on December 16, 2015. Revised on February 16, 2016. Accepted on March 2, 2016. Published online August 19, 2016 pISSN 1976-2283 eISSN 2005-1212 https://doi.org/10.5009/gnl15634

@ This is an Open Access article distributed under the terms of the Creative Commons Attribution Non-Commercial License (http://creativecommons.org/licenses/by-nc/4.0) which permits unrestricted non-commercial use, distribution, and reproduction in any medium, provided the original work is properly cited.
} 
ity and safety of EPLBD for the removal of difficult CBD stones in patients without DLBD. We defined difficult stones as diameter $\geq 10 \mathrm{~mm}^{5}$ To this end, we conducted a retrospective cohort study of patients with or without DLBD.

\section{MATERIALS AND METHODS}

\section{Patients}

Between March 2008 and July 2014, 209 patients underwent EPLBD for the removal of bile duct stones at Yokohama City University Hospital and NTT Tokyo Medical Center. Before initial ERCP, CBD stones were identified in all patients by imaging, including abdominal ultrasonography, computed tomography, or magnetic resonance cholangiopancreatography. The study was approved by the Institutional Review Board of our hospital, and conformed to the provisions of the Declaration of Helsinki (as revised in Fortaleza, Brazil, October 2013).

\section{Definition of without DLBD}

Without DLBD was defined as a state in which the diameter of the lower part of the extrahepatic bile duct was $<10 \mathrm{~mm}$ and its length $>10 \mathrm{~mm}$ as measured by cholangiography. The diameter of the lower part of the bile duct was measured at 10 $\mathrm{mm}$ proximal to the opening of the major ampulla, and we measured the length of the bile duct less than $10 \mathrm{~mm}$ from the opening of the major papilla.

\section{Procedures}

ERCP was performed by experienced biliary endoscopists ( $>200$ procedures annually). All procedures were carried out with the patients under moderate sedation with intravenous diazepam or midazolam. ERCP was performed using side-viewing endoscopes (JF-260V or TJF-260V; Olympus Medical Science Corp., Tokyo, Japan). Cannulation was attempted using an ERCP catheter or a pull-type sphincterotome. Cholangiography was performed to confirm the diagnosis of CBD stones after selective cannulation of the CBD. A 0.035-inch guidewire (Jagwire;
Boston Scientific, Boston, MA, USA) was then inserted into the bile duct through the catheter. A large dilating balloon (CRE, Boston Scientific; GIGA, Century Medical, Tokyo, Japan) was introduced into the bile duct along the prepositioned guidewire and positioned to be able to cover all of the length of without DLBD.

The decision to perform EST was made by the endoscopist based on the patient's background. In particular, EST was carried out in patients with high risk of postprocedural pancreatitis, and avoided in patients with large periampullary diverticula. Balloons were gradually inflated until the balloon notches disappeared, and then they were immediately deflated. EPLBD was terminated upon disappearance of the balloon notches, or if the patient complained of pain, to reduce adverse events. If the patients experienced pain before the maximum pressure was reached, we immediately deflated the balloon before the notches disappeared. Therefore, we did not achieve the maximum pressure. The size of the inflated balloon was selected based on the diameter of the CBD or the largest stone. After EPLBD, a basket or retrieval balloon catheter was used to extract the CBD stones (Fig. 1). ML (Xemex Lithotripsy Basket Catheter; Zeon Medical, Tokyo, Japan) was attempted when stones were too difficult to remove. If stone removal was incomplete, a nasobiliary tube or a plastic stent was placed to prevent cholangitis. All patients were observed in the hospital for at least 72 hours after endoscopic treatment.

In patients with surgically altered anatomy, including Billroth II and Roux-en-Y anastomosis, ERCP was performed using a single-balloon enteroscope (SIF-Q260; Olympus Medical Science Corp.). We did not perform EST in patients with reconstructed intestine because of the high risk of bleeding and perforation.

\section{Outcome measurements and adverse events}

The primary outcomes were the bile duct clearance rate in a single session and the need for additional ML after EPLBD. Although large stones were fragmented during ML, this procedure required more time and resulted in a higher rate of stone
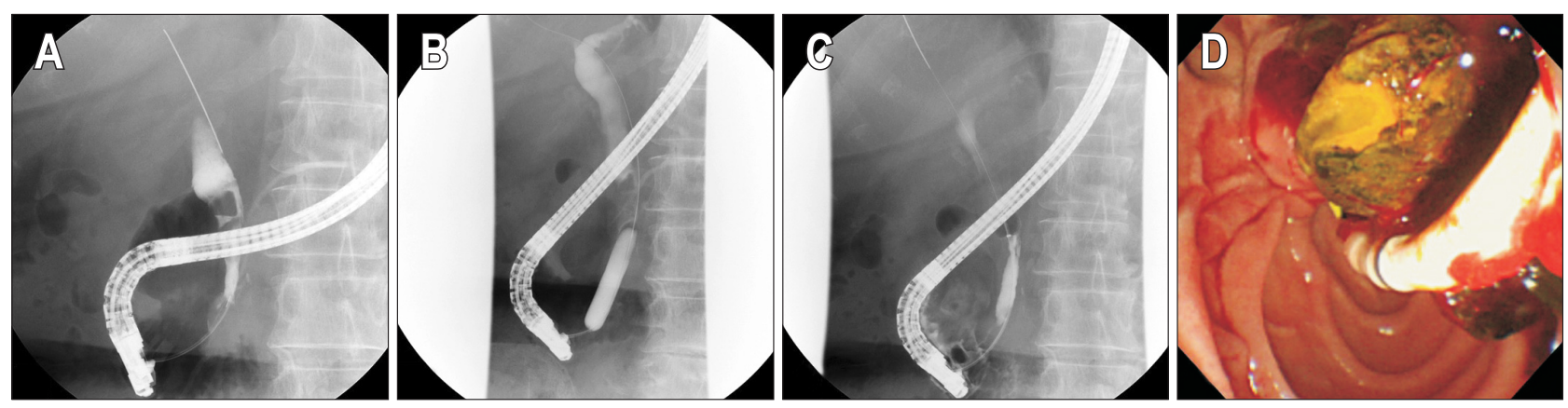

Fig. 1. Endoscopic papillary large balloon dilation (EPLBD) in a patient without dilatation of the lower bile duct. (A) Cholangiography showing multiple movable filling defects and no dilatation of the lower bile duct $(5.7 \mathrm{~mm}$ ). (B) Fluoroscopic view showing disappearance of the balloon waist after gradual inflation with contrast medium. (C) The lower bile duct was dilated (10.3 mm) as the result of EPLBD. (D) Endoscopic view showing a large brown pigment stone. 
recurrence. The secondary outcomes were the incidence of postERCP complications and the recurrence rate after stone removal. Complications included pancreatitis, bleeding and perforation. Procedure-related complications and their incidence were determined according to the definitions and grading systems suggested by the workshop held by the American Society of Gastrointestinal Endoscopy in $2010 .^{6}$

\section{Statistical analysis}

Statistical analysis was carried out using Student t-test and the chi-square test. Multivariate analysis was performed using logistic regression analysis. A value of $\mathrm{p}<0.05$ was considered to be statistically significant. Statistical analysis was performed using Excel-Toukei 2010 for Windows (Social Survey Research Information Co., Ltd., Tokyo, Japan).

\section{RESULTS}

\section{Patient demographics}

The demographics of the 209 patients (113 men, 96 women; mean age, 78.5 \pm 10.7 years) are presented in Table 1 . The patients were divided into groups with and without DLBD. Fiftyseven patients $(27.3 \%)$ were without DLBD. The mean diameter of the lower part of the bile duct was $8.2 \pm 0.9 \mathrm{~mm}$ (range, 7 to $9 \mathrm{~mm}$ ) in the without-DLBD group and $13.3 \pm 2.1 \mathrm{~mm}$ (range, 10 to $16 \mathrm{~mm})$ in the DLBD group $(\mathrm{p}<0.001)$. The greatest diameter of the bile duct was $19.3 \pm 4.5 \mathrm{~mm}$ (range, 12 to $25 \mathrm{~mm}$ ) in the
without-DLBD group and $18.5 \pm 4.8 \mathrm{~mm}$ (range, 12 to $35 \mathrm{~mm}$ ) in the DLBD group ( $\mathrm{p}=0.663)$. Billroth II anastomosis had been performed in two patients (3.3\%) in the non-DLBD group and in five (3.3\%) in the DLBD group ( $\mathrm{p}=0.680$ ). Roux-en-Y anastomosis had been performed in four patients (7.0\%) in the withoutDLBD group and in five (3.2\%) in the DLBD group ( $p=0.424)$. The frequency of EST did not differ significantly between the two groups ( $35.1 \%$ vs $44.1 \%, \mathrm{p}=0.207$ ). The mean diameter of the largest stones was $15.2 \pm 9.2 \mathrm{~mm}$ (range, 10 to $51 \mathrm{~mm}$ ) in the without-DLBD group and $13.7 \pm 4.6 \mathrm{~mm}$ (range, 10 to $30 \mathrm{~mm}$ ) in the DLBD group $(\mathrm{p}=0.165)$. The mean size of the inflated balloon during EPLBD was $14.3 \pm 2.0 \mathrm{~mm}$ (range, 12 to $20 \mathrm{~mm}$ ) in the without-DLBD group and $14 \pm 2.4 \mathrm{~mm}$ (range, 12 to 20 $\mathrm{mm}$ ) in the DLBD group ( $\mathrm{p}=0.040)$. The follow-up period was $26 \pm 19.7$ months (range, 12 to 20 months) in the without-DLBD group and $28 \pm 20.4$ months (range, 1 to 77 months) in the DLBD group.

\section{Outcomes}

The primary outcomes are shown in Table 2. The stone clearance rate was 100\% (57/57) in the without-DLBD group and 98.7\% (150/152) in the DLBD group. Additional ML was required in 33.3\% (19/57) of the without-DLBD group and 23\% (35/152) in the DLBD group ( $p=0.311)$. The mean diameter of the lower part of the bile duct after EPLBD was $11 \pm 1.5 \mathrm{~mm}$ (range, 8 to $13 \mathrm{~mm}$ ) in the without-DLBD group and 14.0 \pm 2.1 $\mathrm{mm}$ (range, 10 to $18 \mathrm{~mm}$ ) in the DLBD group. Table $3 \mathrm{dem}-$

Table 1. Baseline Characteristics of Patients

\begin{tabular}{|c|c|c|c|c|}
\hline Characteristic & Total $(n=209)$ & Without-DLBD group $(n=57)$ & DLBD group $(\mathrm{n}=152)$ & p-value \\
\hline Mean age, yr & $78.5 \pm 10.7(39-95)$ & $78.9 \pm 10.5(39-93)$ & $78.3 \pm 12.5(58-95)$ & 0.697 \\
\hline Sex, male:female & 113:96 & $31: 26$ & $70: 82$ & 0.283 \\
\hline Billroth II anastomosis & $7(3.3)$ & $2(3.3)$ & $5(3.3)$ & 0.680 \\
\hline Roux-en-Y anastomosis & $9(4.3)$ & $4(7.0)$ & $5(3.2)$ & 0.424 \\
\hline \multicolumn{5}{|l|}{ Large balloon dilation } \\
\hline With EST & $87(41.6)$ & $20(35.1)$ & $67(44.1)$ & 0.207 \\
\hline Without EST & $123(58.9)$ & $38(66.7)$ & $85(55.9)$ & - \\
\hline \multicolumn{5}{|l|}{ CBD stones } \\
\hline Mean diameter of stone, $\mathrm{mm}$ & $14.2 \pm 6.2(10-51)$ & $15.2 \pm 9.2(10-51)$ & $13.7 \pm 4.6(10-30)$ & 0.165 \\
\hline \multicolumn{5}{|l|}{ No. of stones } \\
\hline $1 / 2 / 3 />4$ & $65 / 26 / 25 / 90$ & $19 / 5 / 11 / 22$ & $45 / 21 / 14 / 69$ & 0.947 \\
\hline Greatest diameter of bile duct, $\mathrm{mm}$ & $18.8 \pm 4.7(12-35)$ & $19.3 \pm 4.5(12-25)$ & $18.5 \pm 4.8(12-35)$ & 0.663 \\
\hline Diameter of lower part of bile duct, $\mathrm{mm}^{*}$ & $11.3 \pm 3.0(6-18)$ & $8.2 \pm 0.9(7-9)$ & $13.3 \pm 2.1(10-16)$ & $<0.001$ \\
\hline Dilating balloon size, $\mathrm{mm}$ & $14.3 \pm 2.0(12-20)$ & $14.8 \pm 1.8(12-20)$ & $14 \pm 2.4(12-20)$ & 0.400 \\
\hline $\begin{array}{l}\text { Bile duct diameter }<10 \mathrm{~mm} \\
\text { from opening of major papilla, } \mathrm{mm}\end{array}$ & - & $17.9 \pm 4.8(10-30)$ & - & - \\
\hline Follow-up period, mo & $27 \pm 20.2(1-77)$ & $26 \pm 19.7(1-72)$ & $28 \pm 20.4(1-77)$ & 0.600 \\
\hline
\end{tabular}

Data are presented as the mean \pm SD (range) or number $(\%)$.

Diameter of the lower part of the bile duct measured at $10 \mathrm{~mm}$ proximal to the opening of the major papilla.

DLBD, dilatation of the lower part of the bile duct; EST, endoscopic sphincterotomy; CBD, common bile duct. 
Table 2. Results of Stone Clearance with EPLBD

\begin{tabular}{lrr}
\hline \multicolumn{1}{c}{ Variable } & Without-DLBD group (n=57) & DLBD group (n=152) \\
\hline Overall stone removal & $57(100)$ & $150(98.7)$ \\
Complete stone removal in first session & $38(66.7)$ & $117(75.7)$ \\
Additional mechanical lithotripsy & $19(33.3)$ & $35(23.0)$ \\
Diameter of lower part of bile duct after EPLBD, mm & $11 \pm 1.5(8-13)$ & 0.130 \\
Procedure time, min & $58.4 \pm 31.7(13-143)$ & $4.0 \pm 2.1(10-18)$ \\
Reccurence CBD stones & $1(1.8)$ & 0.010 \\
\hline
\end{tabular}

Data are presented as the number (\%) or mean \pm SD (range).

Diameter of the lower part of the bile duct measured at $10 \mathrm{~mm}$ proximal to the opening of the major ampulla.

EPLBD, endoscopic papillary large balloon dilation; DLBD, dilatation of the lower part of the bile duct; CBD, common bile duct.

Table 3. Factors for Additional Lithotripsy by Univariate and Multivariate Analysis

\begin{tabular}{|c|c|c|c|c|c|c|}
\hline \multirow{2}{*}{ Variable } & \multicolumn{3}{|c|}{ Univariate } & \multicolumn{3}{|c|}{ Multivariate } \\
\hline & OR & $95 \% \mathrm{CI}$ & p-value & $\mathrm{OR}$ & $95 \% \mathrm{CI}$ & p-value \\
\hline EST & 0.966 & $0.508-1.839$ & 0.917 & 0.966 & $0.484-1.929$ & 0.922 \\
\hline Reconstructed intestine (B-II or R-Y) & 0.631 & $0.173-2.309$ & 0.487 & 0.612 & $0.154-2.433$ & 0.486 \\
\hline Stone number $>4$ & 1.667 & $0.777-2.768$ & 0.237 & 1.542 & $0.838-3.682$ & 0.204 \\
\hline Diameter of largest stone $>15 \mathrm{~mm}$ & 3.273 & $1.701-6.297$ & $<0.001$ & 3.089 & $1.593-5.991$ & 0.001 \\
\hline Without DLBD & 1.693 & $0.843-3.398$ & 0.139 & 1.757 & $0.838-3.682$ & 0.135 \\
\hline
\end{tabular}

OR, odds ratio; CI, confidence interval; EST, endoscopic sphincterotomy; B-II, Billroth II; R-Y, Roux-en-Y; DLBD, dilatation of lower part of bile duct.

Table 4. Factors for Multiple Sessions by Univariate and Multivariate Analysis

\begin{tabular}{|c|c|c|c|c|c|c|}
\hline \multirow{2}{*}{ Variable } & \multicolumn{3}{|c|}{ Univariate } & \multicolumn{3}{|c|}{ Multivariate } \\
\hline & $\mathrm{OR}$ & $95 \% \mathrm{CI}$ & $\mathrm{p}$-value & $\mathrm{OR}$ & $95 \% \mathrm{CI}$ & p-value \\
\hline EST & 1.287 & $0.701-2.365$ & 0.416 & 1.512 & $0.757-3.019$ & 0.241 \\
\hline Stone number $>4$ & 2.492 & $1.345-4.619$ & 0.004 & 2.984 & $1.489-5.979$ & 0.002 \\
\hline Diameter of largest stone $>15 \mathrm{~mm}$ & 2.654 & $1.429-4.928$ & 0.002 & 1.718 & $0.852-3.465$ & 0.130 \\
\hline Additional ML & 4.788 & $2.422-9.469$ & $<0.001$ & 3.917 & $1.876-8.179$ & $<0.001$ \\
\hline Without DLBD & 1.866 & $0.977-3.566$ & 0.059 & 2.396 & $1.116-5.145$ & 0.025 \\
\hline
\end{tabular}

OR, odds ratio; CI, confidence interval; EST, endoscopic sphincterotomy; ML, mechanical lithotripsy; DLBD, dilatation of lower part of bile duct.

onstrates that absence of DLBD was not an independent risk factor for additional ML as determined by multivariate analysis ( $p=0.135$; odds ratio, $1.757 ; 95 \%$ confidence interval, 0.838 to 3.682).

There was no significant difference in the bile duct clearance rate in a single session between the without-DLBD and DLBD groups ( $100 \%$ vs $98.7 \%, p=0.942 ; 66.7 \%$ vs $75.7 \%$, $p=0.130$, respectively). Multiple sessions of ERCP were required in patients with several stones, additional ML and without DLBD (Table 4). Table 4 reveals that without DLBD was a risk factor for multiple sessions of ERCP by multivariate analysis ( $p=0.025$; odds ratio, 2.396; 95\% confidence interval, 1.116 to 5.145). In addition, the procedure time was significantly longer in the without-DLBD group $(58.4 \pm 31.7$ vs $48.1 \pm 23.0, p=0.010)$. The recurrence rates were not significantly different between the without-DLBD and
DLBD groups (1.8\% vs 4.6\%, $\mathrm{p}=0.581$, respectively).

\section{Complications}

The data on secondary outcomes are shown in Table 5. The rates of post-ERCP pancreatitis (7\% vs 3.3\%, $\mathrm{p}=0.424$ ), perforation ( $0 \%$ vs $1.3 \%, p=0.942$ ), and bleeding ( $1.8 \%$ vs $0.7 \%$, $\mathrm{p}=0.924$ ) were not significantly different between the withoutDLBD and DLBD groups. Similarly, there was no significant difference in the levels of serum amylase after 24 hours (240.8 \pm 318.5 [range, 29 to $1,689 \mathrm{IU}$ ] in the without-DLBD group and $240.5 \pm 315.1$ [range, 22 to 2,465 IU] in the DLBD group, $\mathrm{p}=0.554)$. Although there were six cases of mild and three of moderate pancreatitis, none of the patients developed severe pancreatitis after EPLBD. Two cases of minor perforation in the DLBD group were treated conservatively. Massive bleeding that 
Table 5. Comparison of Complications between the Groups

\begin{tabular}{cccc}
\hline Variable & Non-DLBD group (n=57) & DLBD group (n=152) & p-value \\
\hline Pancreatitis & $4(7)$ & $5(3.3)$ & 0.424 \\
Mild & $3(5.3)$ & $3(2)$ & 0.422 \\
Moderate & $1(1.8)$ & $2(1.3)$ & 0.678 \\
Perforation & 0 & $2(1.3)$ & 0.942 \\
Bleeding & $1(1.8)$ & $1(0.7)$ & 0.924 \\
Major & $1(1.8)$ & 0 & 0.609 \\
Minor & 0 & $1(0.7)$ & 0.609 \\
Amylase after $24 \mathrm{hr}$ & $240.8 \pm 318.5(29-1689)$ & $240.5 \pm 315.1(22-2465)$ & 0.554 \\
\hline
\end{tabular}

Data are presented as the number (\%) or mean \pm SD (range).

DLBD, dilatation of lower part of bile duct.

occurred in one patient in the without-DLBD group was treated by interventional radiology.

\section{DISCUSSION}

This study presents three important clinical observations. First, stone clearance rate in patients without DLBD was 100\%, and it was not an independent risk factor for additional ML. Second, EPLBD appeared to be a safe method for CBD stone removal in patients without DLBD. Third, stone recurrence rate was similar in the patients with and without DLBD.

Recently, EPLBD has been performed in patients with large stones $(>10 \mathrm{~mm})$ and dilated CBDs (>10 mm). Lower complication rates have been reported for EPLBD compared with EST with a large incision for the removal of difficult bile duct stones. ${ }^{3,-10}$ However, there is no consensus regarding the diameter of the lower part of the bile duct suitable for EPLBD. We encountered cases with large stones and tapering of the lower part of the CBD, which might make it difficult to extract the stones by EST or EPBD combined with ML. Therefore, we hypothesized that EPLBD could be extended to include such challenging cases.

EPLBD leads to wide opening of the papillary orifice in patients with large stones, thereby facilitating effective extraction of difficult stones. ${ }^{11,12}$ It can also reduce the use of ML and the overall procedure time. ${ }^{4,13}$ However, the shape of the bile duct amenable to this procedure is a matter of debate. We revealed that stone clearance rate in patients without DLBD was 100\%, but more time and more sessions were required to complete stone removal than in patients with DLBD. A benefit of EPLBD was the wide opening of the papillary orifice. In this study, we dilated the lower part of the bile duct in the without-DLBD group $(8.2 \pm 0.9$ to $11 \pm 1.5 \mathrm{~mm})$. However, the diameter of the lower part of the bile duct after EPLBD in the without-DLBD group was smaller than that of the lower part of the bile duct after EPLBD in the DLBD group $(11 \pm 1.5 \mathrm{~mm}$ vs $14.0 \pm 2.1 \mathrm{~mm}$, $\mathrm{p}<0.001)$. Therefore, we consider that the difference resulted from the number of sessions and the time required. In con- trast, the rate of additional ML did not differ (33.3\% vs 23.0\%, $\mathrm{p}=0.311$ ). In this regard, additional ML was required in $80 \%$ of patients who underwent EPBD. ${ }^{14}$ The diameter of the lower part of the bile duct after EPLBD was extended to $>10 \mathrm{~mm}$, which avoided the need for additional ML. Moreover, more time and sessions were required to treat cases without DLBD with EPBD. These shortcomings of EPBD may be overcome with EPLBD. Therefore, EPLBD against without DLBD was a more useful method to remove the difficult stones than EPBD against without DLBD. In addition, lowering the frequency of additional ML is important to prevent recurrent bile duct stones because stone fragments remaining after lithotripsy can act as nuclei for subsequent stone formation. This suggests that EPLBD in patients without DLBD reduced the recurrence rate more than EPBD did. Reducing the recurrence rate lowers hospitalization costs as well as the risk of cholangitis.

Our target of EPLBD was maximum dilation of the bile duct in a safe range. It was most important to safely enforce EPLBD. EPLBD was also acceptable for CBD stone removal in patients without DLBD provided that the complication rate was the same as in the DLBD group. Post-ERCP pancreatitis, perforation and bleeding are the most important complications related to EPLBD. The hypothetical risk of perforation is higher in patients without DLBD because of direct damage to the pancreas caused by physical compression during balloon dilation. ${ }^{15}$ Additionally, according to a previous study, without DLBD is an independent risk factor for perforation. ${ }^{16}$ In contrast, the rate of pancreatitis did not differ significantly between the two groups in the present study, and there were no instances of perforation in the without-DLBD group. The rate of perforation after EPLBD in patients without DLBD is the most important concern. We suggest that our balloon inflation technique, immediate deflation of the balloon because of pain, and no further dilation, prevented perforation. Lee and Lee ${ }^{16}$ recommended gradual inflation and exercise of caution when persistent notches at the distal CBD is identified after inflation to 75\% of the manufacturer's recommended maximal inflation pressure. Park et al. ${ }^{5}$ reported that if strong resistance is encountered during balloon inflation, ad- 
ditional pressure should not be applied. Our technique is similar to those of Lee and Lee ${ }^{16}$ and Park et al. ${ }^{5}$ If the balloon notches do not disappear even at 75\% of maximal inflation pressure, the pressure should not be increased to near maximum because nearly all patients complained of pain. In an ex vivo porcine model, a bile duct wall tear caused by overdilation of small bile ducts after large-balloon dilation was demonstrated. ${ }^{17}$ In humans, a tear in the lower bile duct does not necessarily lead to direct rupture into the retroperitoneum or peritoneal cavity because the lower bile duct is located within the pancreas. ${ }^{17}$ Therefore, patients without DLBD, who had an extrapancreatic bile duct that was dilated to at least the size of the stone, did not have perforation when using a balloon whose size was decided with reference to bile duct and stone diameters. In this study, all of the balloons were smaller than the maximum diameter of the bile duct outside the pancreas.

The rate of complications in the present study was lower than that of previous studies. ${ }^{18}$ In this respect, both techniques seem to be suitable for the treatment of large bile duct stones. Another possible complication is bleeding, which may be related to excessive ampullary dilation. In the present study, an episode of major bleeding after EPLBD occurred in the DLBD group. This post-ERCP bleeding was associated with damage to the small vessels surrounding the ampulla caused by the radial pressure created by balloon dilation.

There were three limitations to this study. First, the study was limited by its retrospective nature. Second, there could have been variations in balloon size and indications for EST, as the corresponding decisions were at the discretion of the endoscopist in charge. It has been suggested recently that EPLBD without EST is as safe and effective as EST alone for the removal of large bile duct stones. ${ }^{18-20}$ Thus, there is no unified opinion about EST among endoscopists. Third, long-term complications of EPLBD such as recurrence of stones and retrograde infection were not evaluated.

We showed that EPLBD is a safe procedure in patients without DLBD. Furthermore, although the EPLBD procedure in patients without DLBD may require a long time and multiple sessions to complete the stone removal, the rate of additional ML is comparable. The lower rate of additional $\mathrm{ML}$ is expected to reduce the recurrence rate and procedure time when compared with EPBD. A further study comparing the effectiveness of EPLBD and EST with EPBD in patients without DLBD is needed.

In conclusion, this study shows that EPLBD is a useful and safe method for patients in whom the lower part of the bile duct is not dilated. EPLBD for patients without DLBD could dilate the lower bile duct without increasing the complications, and stone clearance rate was 100\%. Our balloon inflation technique, immediate deflation of the balloon because of pain, and no further dilation, may contribute to performing safely EPLBD for patients without DLBD. There was no difference in the rate of additional ML between patients with and without DLBD.

\section{CONFLICTS OF INTEREST}

No potential conflict of interest relevant to this article was reported.

\section{REFERENCES}

1. Staritz M, Ewe K, Meyer zum Büschenfelde KH. Endoscopic papillary dilatation, a possible alternative to endoscopic papillotomy. Lancet 1982;1:1306-1307.

2. Fujita N, Maguchi H, Komatsu Y, et al. Endoscopic sphincterotomy and endoscopic papillary balloon dilatation for bile duct stones: a prospective randomized controlled multicenter trial. Gastrointest Endosc 2003;57:151-155.

3. Ersoz G, Tekesin 0, Ozutemiz A0, Gunsar F. Biliary sphincterotomy plus dilation with a large balloon for bile duct stones that are difficult to extract. Gastrointest Endosc 2003;57:156-159.

4. Itoi T, Itokawa F, Sofuni A, et al. Endoscopic sphincterotomy combined with large balloon dilation can reduce the procedure time and fluoroscopy time for removal of large bile duct stones. Am J Gastroenterol 2009;104:560-565.

5. Park SJ, Kim JH, Hwang JC, et al. Factors predictive of adverse events following endoscopic papillary large balloon dilation: results from a multicenter series. Dig Dis Sci 2013;58:1100-1109.

6. Cotton PB, Eisen GM, Aabakken L, et al. A lexicon for endoscopic adverse events: report of an ASGE workshop. Gastrointest Endosc 2010;71:446-454

7. Kim HG, Cheon YK, Cho YD, et al. Small sphincterotomy combined with endoscopic papillary large balloon dilation versus sphincterotomy. World J Gastroenterol 2009;15:4298-4304.

8. Minami A, Hirose S, Nomoto T, Hayakawa S. Small sphincterotomy combined with papillary dilation with large balloon permits retrieval of large stones without mechanical lithotripsy. World J Gastroenterol 2007;13:2179-2182.

9. Kochhar R, Dutta U, Shukla R, Nagi B, Singh K, Wig JD. Sequential endoscopic papillary balloon dilatation following limited sphincterotomy for common bile duct stones. Dig Dis Sci 2009;54:1578-1581.

10. Heo JH, Kang DH, Jung HJ, et al. Endoscopic sphincterotomy plus large-balloon dilation versus endoscopic sphincterotomy for removal of bile-duct stones. Gastrointest Endosc 2007;66:720-726.

11. Meine GC, Baron TH. Endoscopic papillary large-balloon dilation combined with endoscopic biliary sphincterotomy for the removal of bile duct stones (with video). Gastrointest Endosc 2011;74:1119-1126.

12. Feng Y, Zhu H, Chen X, et al. Comparison of endoscopic papillary large balloon dilation and endoscopic sphincterotomy for retrieval of choledocholithiasis: a meta-analysis of randomized controlled trials. J Gastroenterol 2012;47:655-663.

13. Lee TH, Park SH, Lee CK, Chung IK, Kim SJ, Kang CH. Life-threatening hemorrhage following large-balloon endoscopic papillary dilation successfully treated with angiographic embolization. En- 
doscopy 2009;41 Suppl 2:E241-E242.

14. Fujisawa T, Kagawa K, Hisatomi K, Kubota K, Nakajima A, Matsuhashi N. Endoscopic papillary large-balloon dilation versus endoscopic papillary regular-balloon dilation for removal of large bileduct stones. J Hepatobiliary Pancreat Sci 2014;21:405-409.

15. Draganov PV, Evans W, Fazel A, Forsmark CE. Large size balloon dilation of the ampulla after biliary sphincterotomy can facilitate endoscopic extraction of difficult bile duct stones. J Clin Gastroenterol 2009;43:782-786.

16. Lee DK, Lee BJ. EST, EPBD, and EPLBD (cut, stretch, or both?). In: Niwa H, Tajiri H, Nakajima M, Yasuda K, eds. New challenges gastrointestinal endoscopy. Tokyo: Springer, 2008:385-397.

17. Hisatomi K, Ohno A, Tabei K, Kubota K, Matsuhashi N. Effects of large-balloon dilation on the major duodenal papilla and the lower bile duct: histological evaluation by using an ex vivo adult porcine model. Gastrointest Endosc 2010;72:366-372.

18. Chan HH, Lai KH, Lin CK, et al. Endoscopic papillary large balloon dilation alone without sphincterotomy for the treatment of large common bile duct stones. BMC Gastroenterol 2011;11:69.

19. Jeong S, Ki SH, Lee DH, et al. Endoscopic large-balloon sphincteroplasty without preceding sphincterotomy for the removal of large bile duct stones: a preliminary study. Gastrointest Endosc 2009;70:915-922.

20. Oh MJ, Kim TN. Prospective comparative study of endoscopic papillary large balloon dilation and endoscopic sphincterotomy for removal of large bile duct stones in patients above 45 years of age. Scand J Gastroenterol 2012;47:1071-1077. 